\title{
ARTICLE
}

\section{Extraction of essential oil from the aerial parts of Artemisia frigida Willd by way of hydrodistillation}

\author{
Saranchimeg Borchuluun ${ }^{*}$, Qinghu Wang ${ }^{1}$ and Junsheng Hao ${ }^{1}$ \\ ${ }^{1}$ College of Traditional Mongolian Medicine, Inner Mongolia University for Nationalities \\ Tongliao, PR China
}

ARTICLE INFO: Received: 29 Aug, 2019; Accepted: 23 Jun, 2020

\begin{abstract}
This study aims to determine the optimum conditions for extraction of essential oil compounds in the aerial parts of Artemisia frigida Willd. Method: the considered extraction method is hydro-distillation, using a Clevenger apparatus. The effect of particle size of raw material, soaking time, liquid to plant material ratio and extraction time on essential oil yield were investigated through both single factor and multi-factor experiments. Results: In the single factor experiment, the influences of the following factors on essential oil extraction were studied; particle size $0.825 \mathrm{~mm}$, soaking time $2 \mathrm{~h}$, and liquid to plant material ratio 12:1. Under the multi-factor experiment, the influences of multiple factors of extraction conditions on essential oil were considered, particularly, extraction time $(C)>$ soaking time $(A)>$ liquid to plant material ratio. Conclusion: For extraction of essential oil from the aerial parts of Artemisia frigida Willd, the following optimum extraction parameters were identified: $2 \mathrm{~h}$ of soaking time, 10:1 liquid to solid ratio, and $8 \mathrm{~h}$ of extraction time.
\end{abstract}

Keywords: Artemisia frigida; essential oil; hydrodistillation; agi;

\section{INTRODUCTION}

Artemisia frigida Willd. (Asteraceae) is a perennial herb that reaches up to $10-14 \mathrm{~cm}$ in height. The Artemisia frigida is widespread throughout Central Asian countries (China, Mongolia, and Russia), Europe, Siberia, and North America [1]. Artemisia frigida is an important medicinal plant in traditional Mongolian medicine for its pharmacological application on stanch and detumescence. In Mongolian traditional medicine, Artemisia frigida is locally known as "Agi" $[2,3]$. There are numerous bioactive compounds in the aerial parts of Artemisia frigida, such as flavonoids, terpenoids, tannins, phenols steroids, and organic acids and the most important chemical constituent is essential oil [1, 4]. Many scientists have investigated the chemical composition of essential oil in the aerial parts of Artemisia frigida by $\mathrm{GC} / \mathrm{MS}$, and more than 100 chemical components were isolated and defined [5-7].

*corresponding author: saraa_102@yahoo.com

https://orcid.org/0000-0003-3994-0836

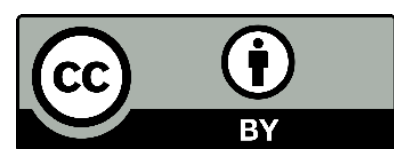

The Author(s). 2020 Open access This article is distributed under the terms of the Creative Commons Attribution 4.0 International License (https://creativecommons.org/licenses/by/4.0/), which permits unrestricted use, distribution, and reproduction in any medium, provided you give appropriate credit to the original author(s) and the source, provide a link to the Creative Commons license, and indicate if changes were made. 
Essential oils are widely used in medicine, health products, and in the cosmetic industry [8]. It has various pharmaceutical properties - it is anti-inflammatory, acts as an antioxidant, and has anticancerous antimicrobial activity [9-11]. Essential oils are essentially bio-active compounds and have a complex mixture of more than 20 different components of low molecular weight, and plant extracted essential oils, in particular, contain terpenes, oxygenated derivative, and other aromatic compounds [12].

Essential oils from various plants can be isolated using several methods, such as hydrodistillation, steam distillation, and organic solvent extraction. Hydro-distillation is the most commonly used method, which has been

\section{MATERIALS AND METHODS}

Plant materials: Aerial parts of Artemisia frigida Willd were collected from the Naiman province of Inner Mongolia, China in August 2018. (The plant was identified by Prof. Bukhbaatar of the Inner Mongolia University for Nationalities)

Extraction method: The essential oil yield of Artemisia frigida (500 g) was obtained by hydro-distillation with a Clevenger type apparatus.

Single factor experiment: The effects of particle size, soaking time, liquid to plant material ratio, and extraction time on essential

\section{RESULTS AND DISCUSSION}

\section{Results of single-factor experiment}

In the single-factor experiment, the following four factors, particle size, extraction time, soaking time, and liquid to plant material ratio, were studied. The results of the experiments are shown in Figures 1-3.

Effect of particle size of the plant material and the extraction time

In the first experiment, the influence of the varying particle size on the yield of the essential oil extraction process was studied. The plant materials were passed through three traditionally used for removal of essential oils from medicinal plants [13]. Several factors may influence extraction efficiency, the particle size, liquid to plant material ratio, whereas soaking and extraction time are crucial factors that affect the extraction process $[14,15]$.

This study aims to define the optimum conditions for the extraction of essential oil compounds from the aerial parts of Artemisia frigida Willd, using the hydro-distillation method.

The objective of this study is to use a single and multi-factor experiment to investigate the influence of the primary factors on the extraction of essential oil components from Artemisia frigida Willd.

oil yield were investigated through a single factor experiment.

Multi-factors experiment (orthogonal test design): Based on the single-factor experiment, orthogonal tests were designed to include three factors and three different levels to optimize the essential oil yield of Artemisia frigida [16]. The orthogonal test L9 $(3)^{4}$ parameters are shown in Table 1.

Statistical analysis: Conducted the range analysis and analysis of variance (ANOVA) with a significance level set at $\mathrm{P}<0.05$.

different standard size sieves (numbers 10, 40, and 60 ) of the following sizes: $>2.0,>0.825$, and $>0.425 \mathrm{~mm}$ (figure 1). The results revealed that the extraction time and particle size of plant materials influenced the yield of essential oil. The essential oil yield increased significantly by roughly $0.24-0.42 \%$ when extraction time was within the range of 4-6 h, and the particle size $>0.825 \mathrm{~mm}$, in other words, the yield of essential oil was at its highest. Therefore, the identified particle size of plant material is considered for further study. 


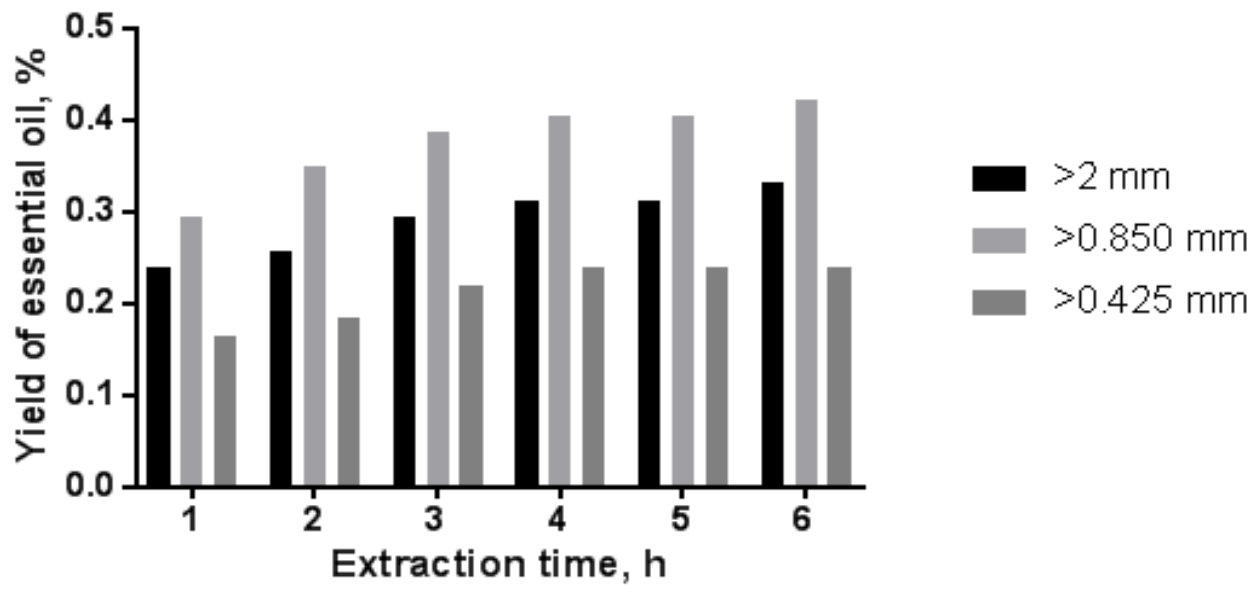

Figure1. Effect of particle size and extraction time on the yield of essential oil

\section{Effect of soaking time}

The effect of soaking time was studied with a particle size of $>0.825 \mathrm{~mm}$, at 10:1 liquid to plant material ratio, and with soaking time ranging from 1 to 6 hours, extracting for 6 hours. Based on the results, it has been found that the essential oil yield $(0.31-0.33 \%)$ is higher when the soaking time is longer. However, beyond 4 hours of soaking time, its effect is insignificant, and the yield of essential oil is roughly the same (figure 2). Therefore, the optimal soaking time was determined as 2 hours.

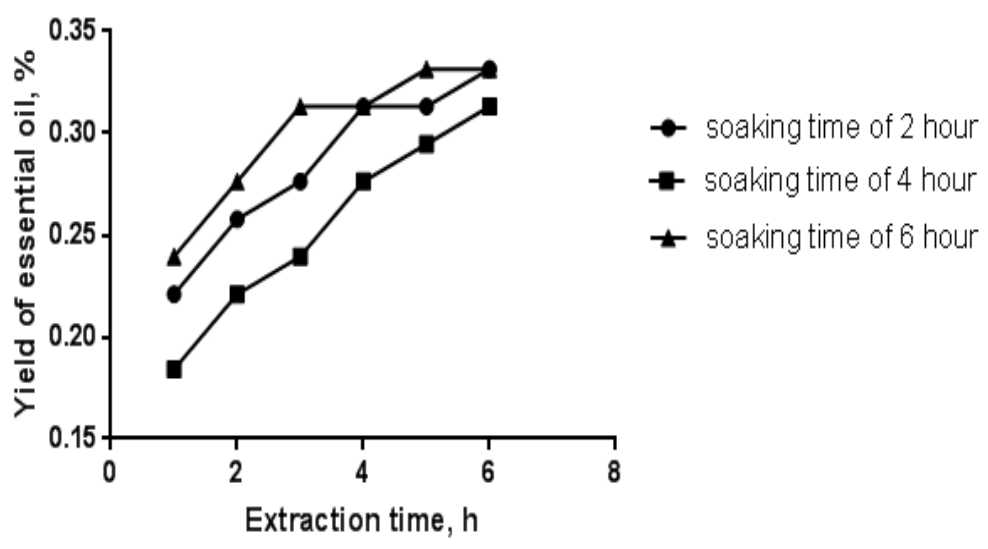

Figure 2. Effect of soaking time on the yield of essential oil

\section{Effect of liquid to plant material ratio}

This study experimented with the essential oil yield in $6 \mathrm{~h}$ of extraction time, soaking the plant material for $2 \mathrm{~h}$ and extracting with above $>0.825 \mathrm{~mm}$ size, using three different liquid to plant material ratios $(8: 1$, $10: 1$, and $12: 1$ ). The lower the ratio of liquid to the plant material ratio, the lower was the yield.
Figure 3 illustrates the effect of liquid to plant material ratio on the yield of essential oil (0.33$0.37 \%$ ), and the yield is higher when the liquid to plant material ratio is higher. As illustrated in Figure 3, most of the essential oil was extracted at the liquid to plant material ratio of 12:1 compared to the yield distilled with two other liquid to plant material ratios. 


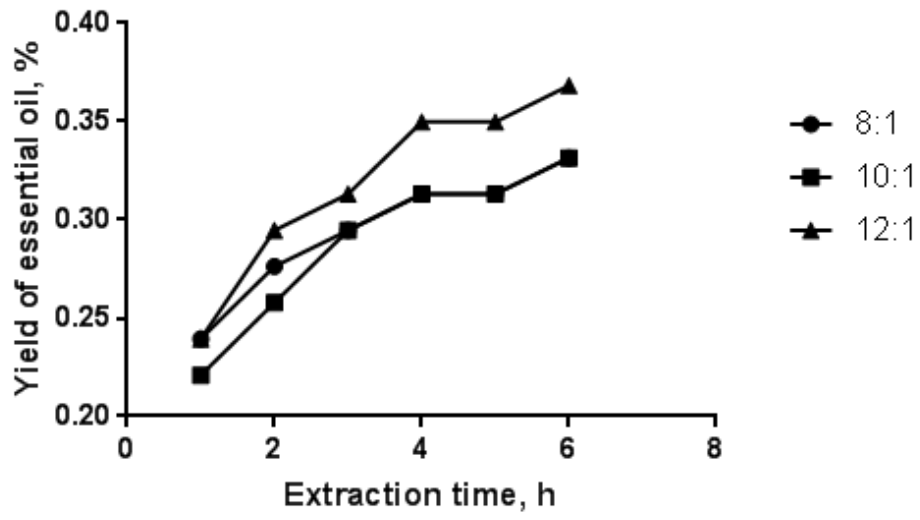

Figure 3. Effect of liquid to plant material ratio on yield of essential oil

Result of multi factor experiment

In multi-factor experiments, the effects of the following four factors were studied soaking time - A, liquid to plant material ratio $\mathrm{B}$, extraction time - C, and blank - D, where every factor has three levels of optimization.
Table 1 summarizes the results of these experiments. The selected factors were assessed by using an orthogonal L9(3)4 test design, and nine extraction experiments were performed. Table 2 contains the schedule and results of the orthogonal test.

Table 1. Factors and levels of orthogonal test

\begin{tabular}{cccc}
\hline & & \multicolumn{3}{c}{ Factors } & \\
\cline { 2 - 4 } Levels & $\mathrm{A}$ & $\mathrm{B}$ & $\mathrm{C}$, \\
& Soaking time (h) & Ratio of liquid to plant material & Extraction time (h) \\
\hline 1 & 2 & $8: 1$ & 4 \\
2 & 4 & $10: 1$ & 6 \\
3 & 6 & $12: 1$ & 8 \\
\hline
\end{tabular}

Table 2. Analysis of 9(34) orthogonal test results

\begin{tabular}{cccccc}
\hline № & $\begin{array}{c}\text { A, soaking } \\
\text { time }(\mathrm{h})\end{array}$ & $\begin{array}{c}\text { B, ratio of solvent to } \\
\text { raw material }\end{array}$ & $\begin{array}{c}\text { C, extraction } \\
\text { time }(\mathrm{h})\end{array}$ & $\begin{array}{c}\text { D, blank factor } \\
\text { Essential oil yield } \\
(\%)\end{array}$ \\
\hline 1 & 1 & 1 & 1 & 1 & 0.35 \\
2 & 1 & 2 & 2 & 2 & 0.405 \\
3 & 1 & 3 & 3 & 3 & 0.424 \\
4 & 2 & 1 & 2 & 3 & 0.35 \\
5 & 2 & 2 & 3 & 1 & 0.368 \\
6 & 2 & 3 & 1 & 2 & 0.295 \\
7 & 3 & 1 & 3 & 2 & 0.35 \\
8 & 3 & 2 & 1 & 3 & 0.313 \\
9 & 3 & 3 & 2 & 1 & 0.368 \\
K1 & 0.393 & 0.35 & 0.319 & 0.362 & \\
K2 & 0.338 & 0.362 & 0.374 & 0.35 & \\
K3 & 0.344 & 0.362 & 0.381 & 0.362 & \\
R & 0.055 & 0.012 & 0.062 & 0.012 & \\
\hline
\end{tabular}

Table 3. Results of variance analysis

\begin{tabular}{cccccc}
\hline Factor & $S S$ & $D f$ & $M S$ & $F$ & $p$ \\
\hline A & 0.006 & 2 & 0.003 & 18.25 & $>0.05$ \\
B & 0 & 2 & 0 & 1 & $>0.05$ \\
C & 0.007 & 2 & 0.003 & 22.75 & $<0.05$ \\
\hline
\end{tabular}


Through intuitive and variance analysis of the orthogonal experiments of the various factors of the extraction condition, it can be concluded that the extraction time has the highest impact, and the soaking time has a greater weight compared to the liquid to plant material ratio (extraction time $>$ soaking time $>$ liquid to plant material ratio). As shown in the analysis of variance (Table 3 ), extraction time has statistically significant influences. The optimal process combination for extraction of essential oil is $\mathrm{A} 1 \mathrm{~B} 2 \mathrm{C} 3$, which means $2 \mathrm{~h}$ of soaking time, liquid to solid ratio of $10: 1$, and 8 $\mathrm{h}$ of extraction time.

The quality and yield of bioactive compounds from plant material are influenced by the geographic location, harvesting season, the choice and stage of drying conditions, and extraction method [17]. In this experiment, we studied only one assortment of plant material Artemisia frigida plant and determined the optimum conditions for essential oil component extraction of aerial parts of Artemisia frigida; focusing on particle size, soaking time, liquid to plant material ratio, and extraction time by using the hydro-distillation method. The

\section{CONCLUSIONS}

The optimum extraction parameters for extraction of essential oils from the aerial parts of Artemisia frigida Willd were as follows: soaking time $-2 \mathrm{~h}$, liquid to solid ratio $10: 1$, extraction time $-8 \mathrm{~h}$.

\section{REFERENCES}

1. Ligaa, U., Davaasuren, B., Ninjil, N. (2005). Mongolian Medicinal Plants Used in Western and Eastern Medicine. Ulaanbaatar: JKC Printing.

2. Luvshan. (2006). Mongolian Medicine. Hohhot: People's Press Committee.

3. Liu, Y., Liu, J.G., Tang, L., Zhang, W., Zhang, L.X., et al. (2008). Current research situation of "Agei" Mongolian medicine. Studies of Trace Elements and health, pp. 25, 55-57.

4. Wang, Q.H., Wang, J.H., Eerdunbagen, T. (2009). Chemical constituents of Artemisia particle size of herbal material has the most significant effect on the extraction process. When the particle size is smaller, it has a considerably larger surface area and increased the contact area with the solvent [18]. On the other hand, finer particle sizes are more prone to agglomeration, which could hinder the extraction process. Thus, the most effective particle size for extraction should be able to maximize the surface area for mass transfer, yet prevent agglomeration. This study investigated the effect of particle size ranging from 0.425 $\mathrm{mm}$ to $2.0 \mathrm{~mm}$ on yield of essential oils of Artemisia frigida (Figure 1). The plant material crushed to a particle size of $0.425 \mathrm{~mm}$, which had the lowest extraction efficiency, while the highest extraction efficiency was at the particle size of $0.825 \mathrm{~mm}$. Also, it assessed the yield of three different liquids to the plant material ratio and soaking time. The yield of essential oil increases with the increment of liquid to plant material ratio (figure 2) and soaking time (figure 3); however, based on variance analysis of multi-factor examination (Table 3 ), this ratio did not demonstrate a significant impact.

\section{Acknowledgements}

This study was supported by the Inner Mongolia University for the Nationalities, Inner Mongolia, Tongliao, People's Republic of China. frigida. Chinese Traditional and Herbal Drugs, 40(10), pp. 1540-1543.

5. Zhigzhitzhapova, S.V., Randalova, T.E, Radnaeva L.D., Dylenova, E.P., Chen, Sh.L., Zhang, F.Q. (2017). Chemical composition of essential oil of Artemisia frigida Willd. (Asteraceae) grown in North and Central Asia. Journal of Essential Oil Bearing Plants, 20(4), pp. 915-926. Retrieved from https://www.tandfonline.com/.

6. Yang, L.Q., Li, Z.Ch., Xiao, D.H., Zhang, L. (2005). Study on chemical constituents of volatile oil from Mongolian medicine 
Artemisia frigida Willd. Chinese Journal of Analysis Laboratory, 24: p. 45.

7. Korolyuk, E.A., Tkachev, A.V. (2010). Chemical composition of essential oil from two Wormwood species Artemisia frigida and Artemisia argyrophylla. Russian Journal of Bio-organic Chemistry, 36(7), pp. 884-893. Retrieved from https://link.springer.com/.

8. Ali, B., Al-Wabel, N.A., Shams, S., Ahamad, A., Khan, Sh.A., Anwar, F. (2015). Essential oils used in aromatherapy: A systemic review. Asian Pacific Journal of Tropical Biomedicine, 5(8), pp. 601-6011. Retrieved from https://www.sciencedirect.com/.

9. Lopez, L.D., Alviano, D.S., Alviano, C.S., Kolodziejczyk, P.P. (2008). Screening of chemical composition, antimicrobial and antioxidant activities of Artemisia essential oil. Phytochemistry, 69(8), pp. 1732-1738. Retrieved from https://www.sciencedirect.com/.

10. Wang, Q.H., Jin, M.J., Dai, N., Han, N., Han, J.J., Bao, B. (2016). Antiinflammatory effects, nuclear magnetic resonance identification, and highperformance liquid chromatography isolation of the total flavonoids from Artemisia frigida. Journal of food and drug analysis, 24(2), pp. 385-391.

11. Sharififi-Rad, J., Sureda, A., Tenore, G.C., Daglia, M., et al. (2017). Biological Activities of Essential Oils: From Plant Chemoecology to Traditional Healing Systems. Molecules, 22(1), pp. 2-55. Retrieved from https://www.mdpi.com/.
12. Hesham, H.A., Rassem, Abdurahman, H., Nour, Rosli, M., Yunus. (2016). Techniques for extraction of essential oils from plants: A Review. Australian Journal of Basic and Applied Sciences, 10(16), pp. 117-127. http://www.ajbasweb.com/.

13. Zhao, H., Zhang, J.S., Li, L.H., et al. (2006). Plant essential oil extraction technology. Liaoning University of Petroleum University of Chemical Technology, 26 (4), pp. 137-140.

14. Azwanida, N.N. (2015). A review on the extraction methods use in medicinal plants, principle, strength and limitation. Medicinal and Aromatic Plants, 4(3), pp. 1-8. https://www.longdom.org/.

15. Seda D.E.B. (2010). The effects of time, temperature, solvent:solid ratio and solvent composition on extraction of total phenolic compound from dried olive (Olea europaea l.) leaves. The Journal of Food, 35(6) pp. 47.

16. Du, P.L., Zhou, Y.Q., Liang, D., Wei, J.L., Huang, G.H., Zhu, H. (2017). Extraction process of Cinnamomi oleum in Guangxi. Journal of zhuang and yao ethnic medicine, 1, pp. 135-141.

17. Patrautanu, O.A., Lazar, L., Popa, V.I., Volf, I. (2019). Influence of particle size and size distribution on kinetic mechanism of spruce bark polyphenols extraction. Cellulose chemistry and technology, 53 (1), pp. 71-78.

18. Hu, X.L., Gao, Y., Liu, Ch. R., et al. (2006). Orthogonal lavender essential oil extraction process. Food Science, 27 (8), pp. 198 - 199. 